\title{
Пиролитическая хроматография для геохимических исследований нефтеносных горных пород: новый взгляд на классический метод
}

\section{P.С. Герасимов,} Frontier Lab, Корияма, Япония

УдК 543.544.054.92 roman@frontier-lab.com

К.С. Свирский, Agilent Technologies, Санта-Клара, США konstantin.svirskiy@agilent.com

\begin{abstract}
Предложен альтернативный способ (Пиро-ГХ/МС) проведения пиролиза различных геологических объектов, не уступающий по ряду факторов классическому исполнению на популярных системах для геохимической характеризации горных пород. Описаны объекты исследования (образцы нефтематеринской породы и керогена), а также применяемое пиролитическое оборудование, которое представляет собой схему «пиролизер - хроматограф - масс-спектрометрический детектор". Показано, что с помощью Пиро-ГХ/МС можно снимать масс-спектры выделяющихся газов (продуктов пиролиза) с возможностью идентификации групп компонентов или отдельных соединений. Удалось продемонстрировать, что основные пиролитические параметры S1, S2, S3, Tmaх очень хорошо определяются методом Пиро-ГХ/МС, при этом метрологические параметры сопоставимы с аналогичными данными, полученными с помощью классического пиролизатора горных пород. В качестве примера рассмотрена совокупность серосодержащих соединений, которые образуются в результате пиролиза керогена, выделенного из пиритсодержащей нефтематеринской породы.
\end{abstract}

Потребность мировой экономики в энергии вынуждает искать новые источники и разрабатывать технологии для повышения эффективности использования традиционных ресурсов. Несмотря на развитие такихальтернативных направлений, как конверсия растительного сырья в биотопливо или преобразование солнечного излучения, углеводороды пока остаются главным источником энергии и, что немаловажно, самым дешевым. Однако поиск и разработка новых месторождений очень ресурсоемкое занятие, поэтому основной критерий эффективности таких работ состоит в объективной оценке запасов и условий залегания углеводородов, которая невозможна без тщательного всестороннего геохимического анализа нефтеносных породколлекторов. При сборе информации о таких объектах одна из самых важныххарактеристик-тип органического вещества (ОВ), которое вмещает исследуемая порода.

Специалисты компании Frontier Laboratories разработали протокол анализа нефтеносных горных пород с использованием пиролитической приставки для газовой хроматографии [1].
Предложенное инструментальное решение позволяет не только определить традиционные геохимические показатели, но также дает возможность получить дополнительную полезную информацию об образце и, как следствие, сократить затраты на проведение эксперимента и избавиться от трудоемкой процедуры пробоподготовки. Методика требует небольшого количества вещества, обычно 300-500 мкг. Первый этап - применение режима выделяющихся газов (Evolved Gas Analysis или EGA) с использованием программирования температуры пиролитической приставки в традиционном для этого подхода интервале. Полученная ЕGА-пирограмма в дальнейшем используется как отправная точка для последующих анализов образца в других режимах, также реализуемых на пиролитической приставке.

Методика прошла успешную аттестацию во Всероссийском научно-исследовательском институте метрологической службы и имеет соответствующее свидетельство об аттестации (№ 20502/RA.RU.311787-2016/2018) [2]. 


\section{СХЕМА ЭКСПЕРИМЕНТА}

На первом этапе при реализации режима ЕСА пиролитическая приставка позволяет полностью имитировать работу общеизвестных в данной области коммерчески доступных систем, таких как Rock-Eval 6 (Vinci Technologies, France), SRA (Weatherford Laboratories, USA) и HAWK (Wildcat Technologies, USA). Принцип работы этих приборов следующий: образец помещается в печь, температура которой программируется в диапазоне от 100 до 800 $\mathrm{C}$, а на выходе с помощью пламенно-ионизационного детектора регистрируются углеводороды, термодесорбирующиеся из образца или образовавшиеся в результате крекинга ОВ. Неорганические продукты термического воздействия на образец (в основном СО и $\mathrm{CO}_{2}$ ) регистрируются в инфракрасной ячейке. Детектирование свободных углеводородов (продукты термодесорбции), обозначаемых, как это принято, SI, происходит при температуре печи -300 $\mathrm{C}$. Образовавшиеся в процессе термического разложения нерастворимых органических веществ углеводороды пиролиза (S2) регистрируются при дальнейшем нагреве образца в диапазоне температуры печи от 400 до $650^{\circ} \mathrm{C}$ со скоростью $25^{\circ} \mathrm{C} /$ мин. Содержание $\mathrm{CO}_{2}$, образовавшегося при $400{ }^{\circ} \mathrm{C}$, используется для оценки органически связанного кислорода. Наибольший интерес для геохимиков представляет компонент S2, а также апекс его пика, по которому рассчитывается такой важный параметр, как Tmax, характеризующий зрелость ОВ породы.

Работу печи выполняет пиролитическая приставка, а все продукты, как органические, так и неорганические, детектируются на квадрупольном масс-селективном детекторе, сопряженном с газовым хроматографом. Приставка монтируется на испаритель хроматографа, который соединен с масс-селективным детектором капилляром из деактивированной стали без нанесенного слоя неподвижной фазы. На втором этапе исследования полый капилляр меняют на капиллярную хроматографическую колонку для установления индивидуального компонентного состава каждой зоны пиролиза, а масс-селективный детектор в этом случае гораздо информативней при идентификации индивидуальных соединений.

\section{ОПРЕДЕЛЕНИЕ S1, S2, S3 И TMax}

Для проведения эксперимента использовали систему для ГX/MC Agilent 7890 / 5977 GC/ MSD, пиролитическую приставку Frontier Laboratories EGA/PY3030D Pyrolyzer в режиме EGA с капилляром UltraAlloy (длина 2,5 м, Ø0,15 мм). Результаты измерения S1, S2, S3 (m/ z=44) и Tmax для образца свиты Вульфкемп (пермский нефтегазоносный бассейн Западного Техаса) полностью сопоставимы с данными, полученными на инструменте RockEval 6. Оба прибора были откалиброваны по одному стандарту IFP 160000, на каждом приборе сделано по шесть параллельных измерений, результаты приведены на рис. 1 и в табл. 1.

Пирограмма, полученная с помощью Пиро-ГХ/МС в режиме EGA-MS для образца свиты Вудфорд (Оклахома), позволила получить дополнительную информацию об образце, которая не доступна на традиционных системах. Дополнительный пик, появляющийся на хвосте S2 при температуре около $550^{\circ} \mathrm{C}$, свидетельствует о присутствии серосодержащих соединений. Они разлагаются до $\mathrm{H}_{2} \mathrm{~S}, \mathrm{SO}_{2}, \operatorname{COS}$ и $\mathrm{CS}_{2}$, присутствие которых в продуктах пиролиза можно подтвердить с помощью хроматограмм по выделенным специфическим ионам для каждого серосодержащего продукта (m/z 34, 48, 60, 64 и 76) (рис. 2в). На рис. 2а и б представлены две пирограммы: а - необработанного образца, б - керогена, экстрагированного из того же образца. Обе пирограммы идентичны за исключением пика, отвечающего за серосодержащие соединения. Температура, при которой выделяются эти вещества, свидетельствует о том, что сера в основном представлена неорганическими веществами, вступающими в реакцию с керогеном. По площади пика можно оценить количество серосодержащих веществ, а вот на традиционных системах этот параметр пока не доступен исследователю.

Таблица 1. Результаты измерения S1, S2, S3 и Tmax, полученные на Rock-Eval 6 и Пиро-ГХ/МС для образца свиты Вульфкемп

\begin{tabular}{|l|r|r|}
\hline Тип инструмента & Rock-Eval & EGA-MS \\
\hline S1 (мг/г) & 3,74 & 3,76 \\
\hline CKO & 0,05 & 0,12 \\
\hline S2 (мг/г) & 7,93 & 7,31 \\
\hline CKO & 0,17 & 0,07 \\
\hline S3 (мг/г) & 0,32 & 0,33 \\
\hline CKO & 0,04 & 0,02 \\
\hline Tmax $\left({ }^{\circ} \mathrm{C}\right)$ & 452 & 454 \\
\hline CKO & 0,6 & 0,9 \\
\hline
\end{tabular}

Puc. 1. Пирограммы образиа, полученные на RockEval 6 (a)

и на Пиро-ГХ/MC в режиме EGA-MS (6)

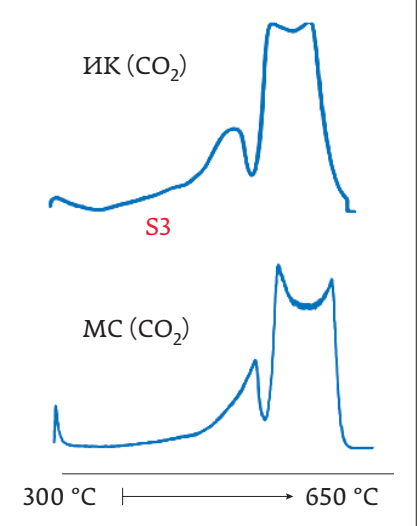

a) S1 S2

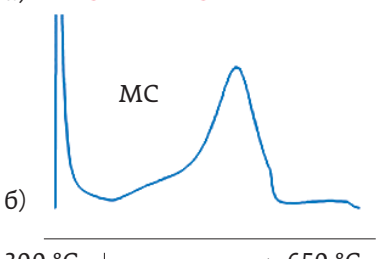

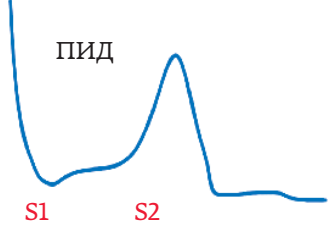




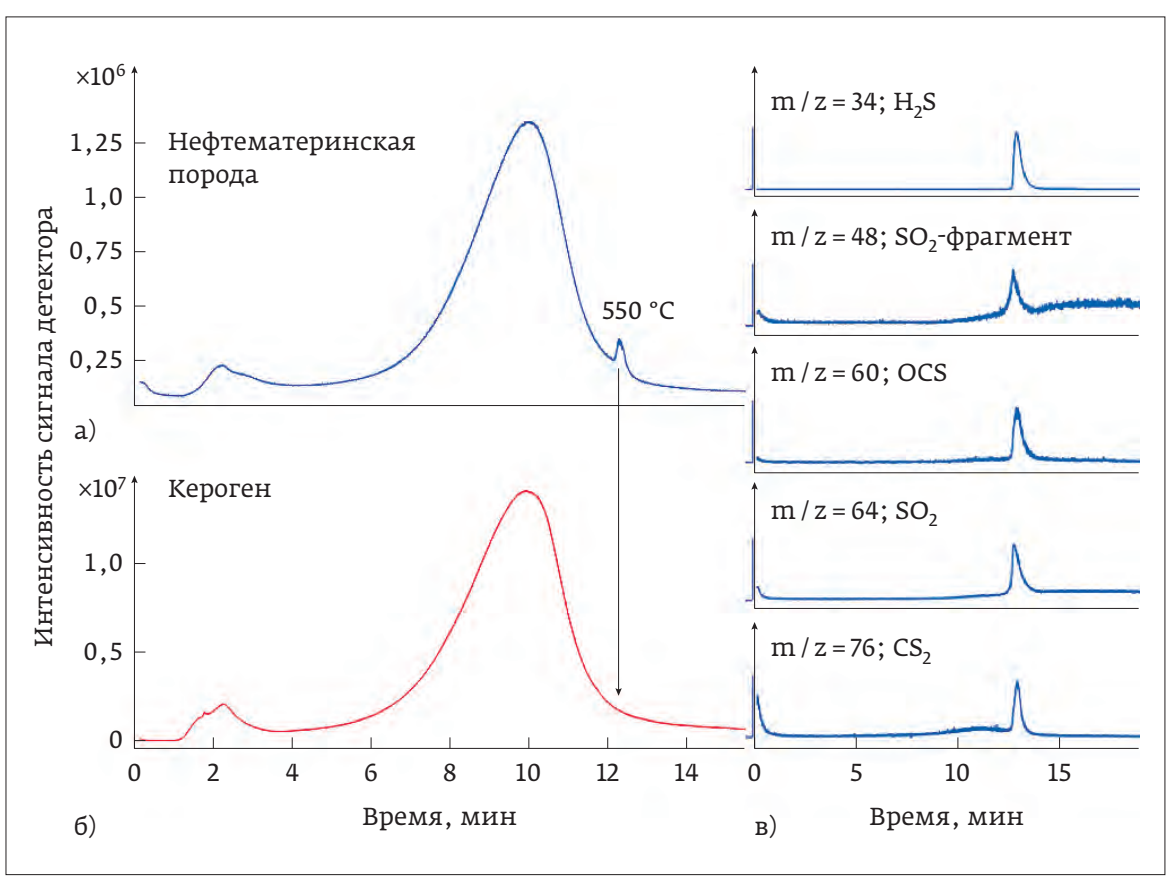

Puс. 2. Пирограммы образца свиты Вудфорд, полученные на Пиро-ГХ/МС: а- необработанный образец; б - кероген, экстрагированный из того же образиа; в - хроматограммы по выделенным ионам

\section{АНАЛИЗ ПРОДУКТОВ ТЕРМОДЕСОРБЦИИ И ПИРОЛИЗА}

После определения основных величин S1, S2, S3 и Tmax капилляр заменили на хроматографическую колонку Ultra ALLOY-5 (30 м; 0,25 мм; 0,25 мкм). Для уверенного разделения легких углеводородов в продуктах термодесорбции и пиролиза ОВ на участке со стороны начала колонки была установлена криоловушка MicroJet, в которой подерживалась температура $-190^{\circ} \mathrm{C}$. Для детального компонентного анализа пика S1 образец нагрели в пиролитической приставке от 100 до $300^{\circ} \mathrm{C}$ со скоростью $25^{\circ} \mathrm{C} /$ мин. Затем образец, не удаляя из пиролитической приставки и не допуская контакта с атмосферой, вынесли за пределы горячей зоны для подготовки ко второму этапу. В это же время происходило хроматографическое разделение продуктов термодесорбции. После завершения сбора данных первой хроматограммы пиролитическую ячейку нагрели до $650^{\circ} \mathrm{C}$, а образец повторно поместили в горячую зону и подвергли пиролизу. Результаты обоих этапов Пиро-ГХ/МС-анализа продуктов термодесорбции и пиролиза представлены на рис. 3. Хроматограммы регистрировали по полному ионному току (TIC).
Пики, соответствующие временам выхода нормальных парафинов обозначены на хроматограммах номером, равным числу атомов углерода в молекуле. Пристан и фитан были уверено обнаружены на хроматограмме фракции $\mathrm{S} 1$ после выхода н-C17 и н-C18 соответственно, что подтверждается сигналами по характеристическим ионам (m / z 55 и 57).

Детальный анализ фракции S2 также несет массу полезной информации. Обнаружен ряд биомаркеров, характеризующих обстановку осадконакопления, литологические условия, зрелость и тип ОВ. После детального анализа хроматограммы фракции S2, полученной в режиме полного сканирования, были проведены эксперименты с накоплением сигнала по отдельным специфическим ионам (m/ z 184, 198 и 212), характерным для ароматических соединений, таких как дибензотиофен и его гомологи (рис. 4). Анализируя SIM-хроматограмму по иону 191,2, можно получить сведения о трициклических терпенах и, например, соотношении таких важнейших биомаркеров, как гопаны С27 (рис. 5). Таким образом, с помощью одного инструмента геохимики способны решить ряд стоящих перед ними первостепенных задач, благодаря информативности метода, совмещенной с простотой эксперимента.

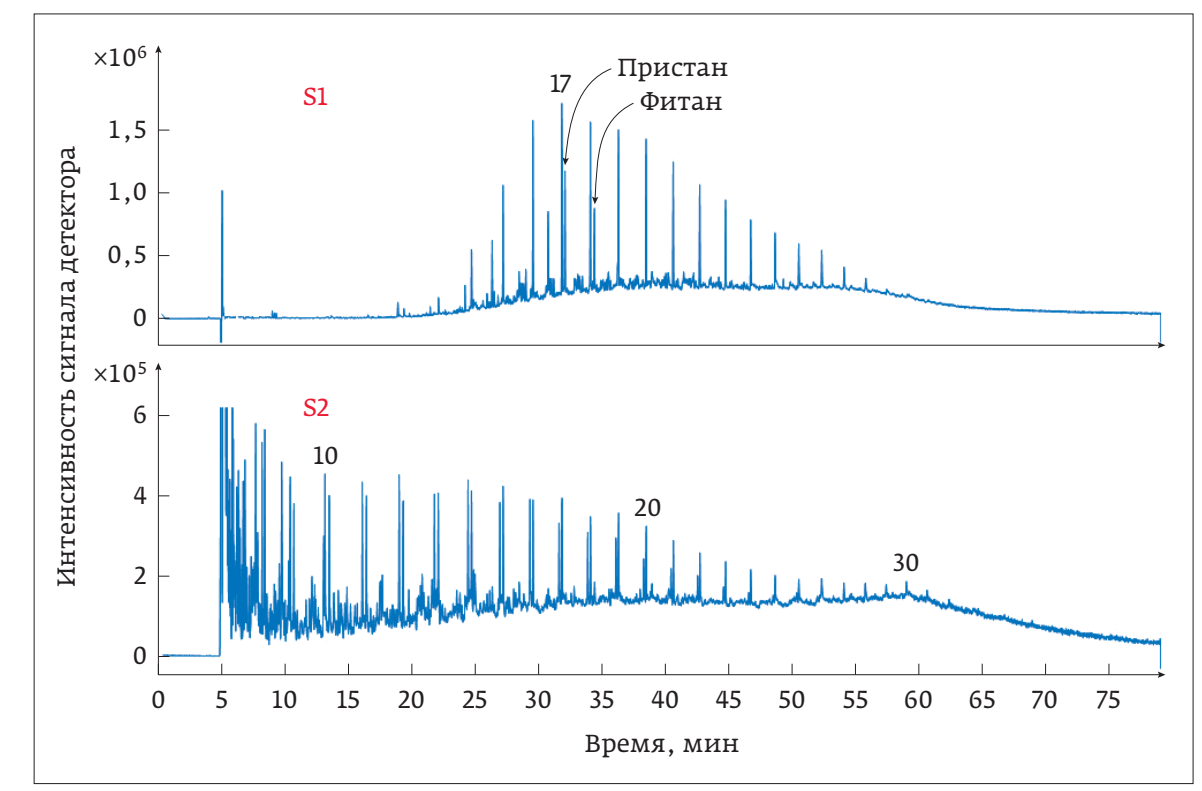

Puc. 3. TIC-хроматограммы компонентного состава фракций S1 и S2 


\section{Достоинства EGA/PY-3030D}

- Отсутствие пробоподготовки

- Продуманный дизайн

- Легкость в настройке

Техническая спецификация:

- Диапазон рабочей температуры:

Комнатная температура $+10^{\circ} \mathrm{C}$ до $1050^{\circ} \mathrm{C}$ с шагом в $1^{\circ} \mathrm{C}$

- Стабильность температуры: $\pm 0.1^{\circ} \mathrm{C}$

- Максимальная скорость нагрева печи: $600^{\circ} \mathrm{C} /$ мин

Время охлаждения печи с $800^{\circ} \mathrm{C}$ до $40^{\circ} \mathrm{C}:<10$ мин

- Оптимальная конструкция печи

- Надежность

- Простое программное обеспечение

- Универсальность

- Высокая информативность

- Совместимость с наиболее популярными системами для газовой хроматографии

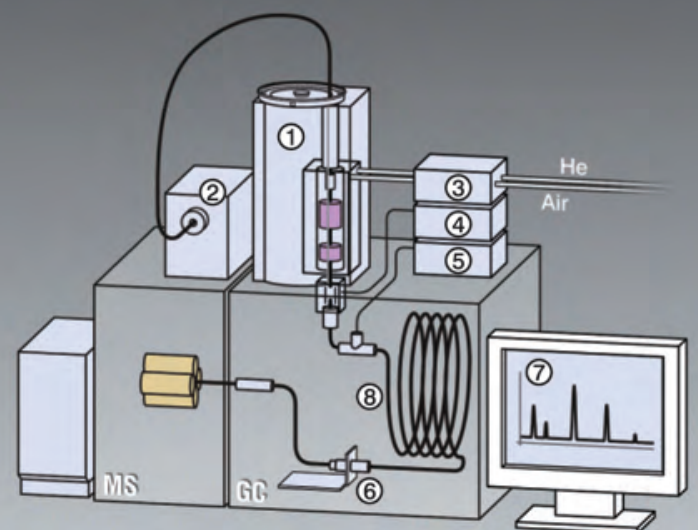

Принципиальная схема системы для пиролитической хроматографии
(1) Автоматический податчик проб
(2) Модуль для УФ-облучения образца
(3) Контроллер газов
(4) Модуль селективного выделения пиролизата
(5) Криоловушка MicroJet
(6) Vent-free адаптер для ГХ/MC
(7) Программное обечпечение F-Search
(8) Хроматографическкя колонка Ultra ALLOY

Один инструмент - множество аналитических режимов
а) Адаптер для многостадийного пиролиза
b) Адаптер для реакционного пиролиза
c) Адаптер для термодесорбции
d) Зонд для УФ-облучения образца
е) Адаптер для ввода жидких проб

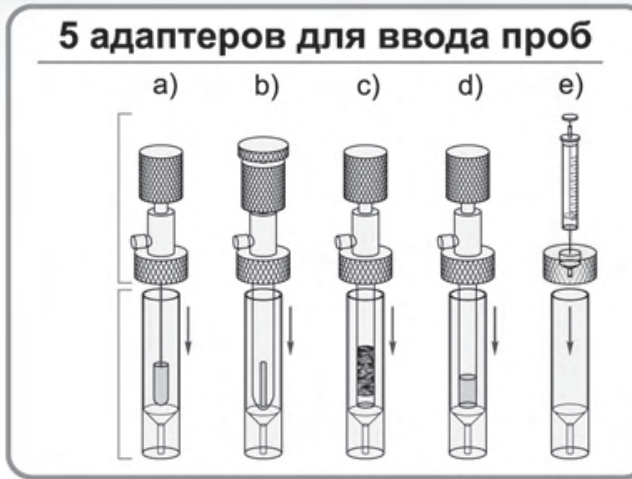

\section{(O) FROCTIER LABORATORIES LTD. www.frontier-lab.ru}




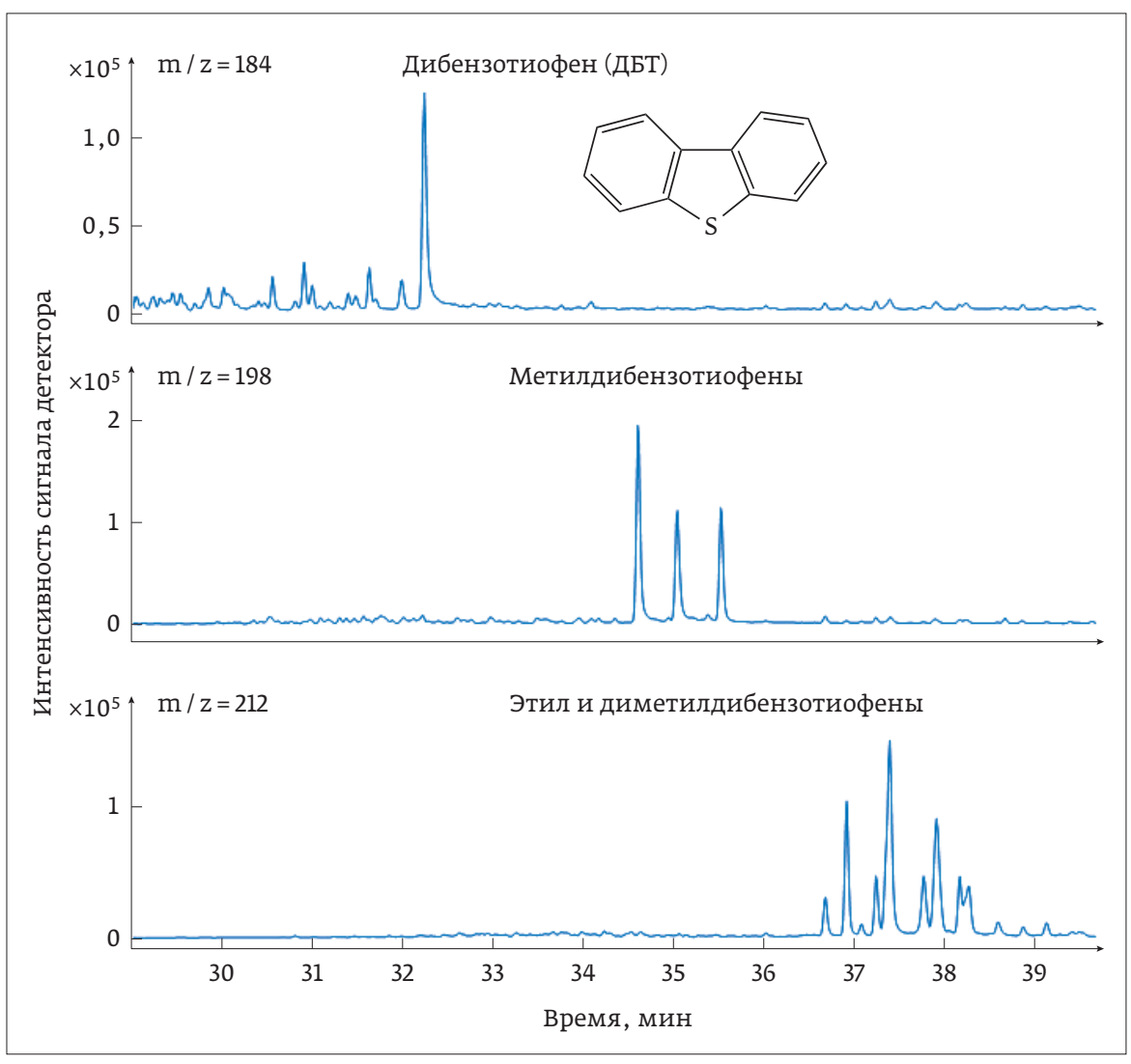

Puc. 4. SIM-хроматограммы дия дибензотиофенов

\section{АЛЬТЕРНАТИВНЫЕ ТЕМПЕРАТУРНЫЕ РЕЖИМЫ ПИРОЛИЗА ОВ}

Время больших открытий залежей углеводородов заканчивается, интенсивно разрабатываются сланцевые месторождения с применением горизонтального бурения и последующим гидроразрывом пласта, поэтому ряд специалистов предлагает многоступенчатый пиролиз для образцов исследуемых пород, так как разделение фракций S1 и S2 в традиционном температурном режиме не всегда приводит к удовлетворительному результату. Как правило, затруднения вызывает "горб" на фронтальном подъеме пика S2, для уверенной оценки которого применяются многоступенчатые температурные программы пиролиза ОВ. Одна из таких программ [3] предписывает разделение продуктов пиролиза на три фракции - Sho, Shl и Sh2. Sh0 состоит из группы веществ, выделяющихся в диапазоне температур от 100 до $200^{\circ} \mathrm{C}$ (скорость нагрева $\left.-25^{\circ} \mathrm{C} / \mathrm{Mин}\right) ; \mathrm{Shl}$ - от 200 до $350^{\circ} \mathrm{C}$ и Sh2 - от 350 до $650^{\circ} \mathrm{C}$. Перед каждым подъемом температуры есть небольшой изотермический участок длительностью три минуты. Другие авторы [4] разбивают программу на сегменты с шагом в $50^{\circ} \mathrm{C}$ и с более длительным изотермическим плато. Однако такой сложный алгоритм увеличивает время эксперимента и снижает чувствительность методики при традиционном подходе с регистрацией сигнала на пламенно-ионизационном детекторе, поскольку при плавном нагреве ширина пиков возрастает. Использование массселективного детектора исключает этот недостаток и дает аналогичную картину (рис. 6), но при гораздо меньших навесках образца, что снижает нагрузку на прибор и частоту его регулярного обслуживания.

\section{ЗАКЛЮЧЕНИЕ}

Сегодня все больше лабораторий обращаются к методу Пиро-ГХ / МС, оценив его преимущества для изучения ОВ нефтеносных пород. Пиролитическая приставка Multi-Shot Pyrolyzer PY-3030D компании Frontier Lab, оснащенная вертикальной прецизионной микропечью для нагрева образца и криоловушкой MicroJet, все чаще находит применение в лабораториях органической геохимии как для реализации традиционного алгоритма по методу Rock Evaluation, так и для проведения экспериментов по изучению индивидуального состава

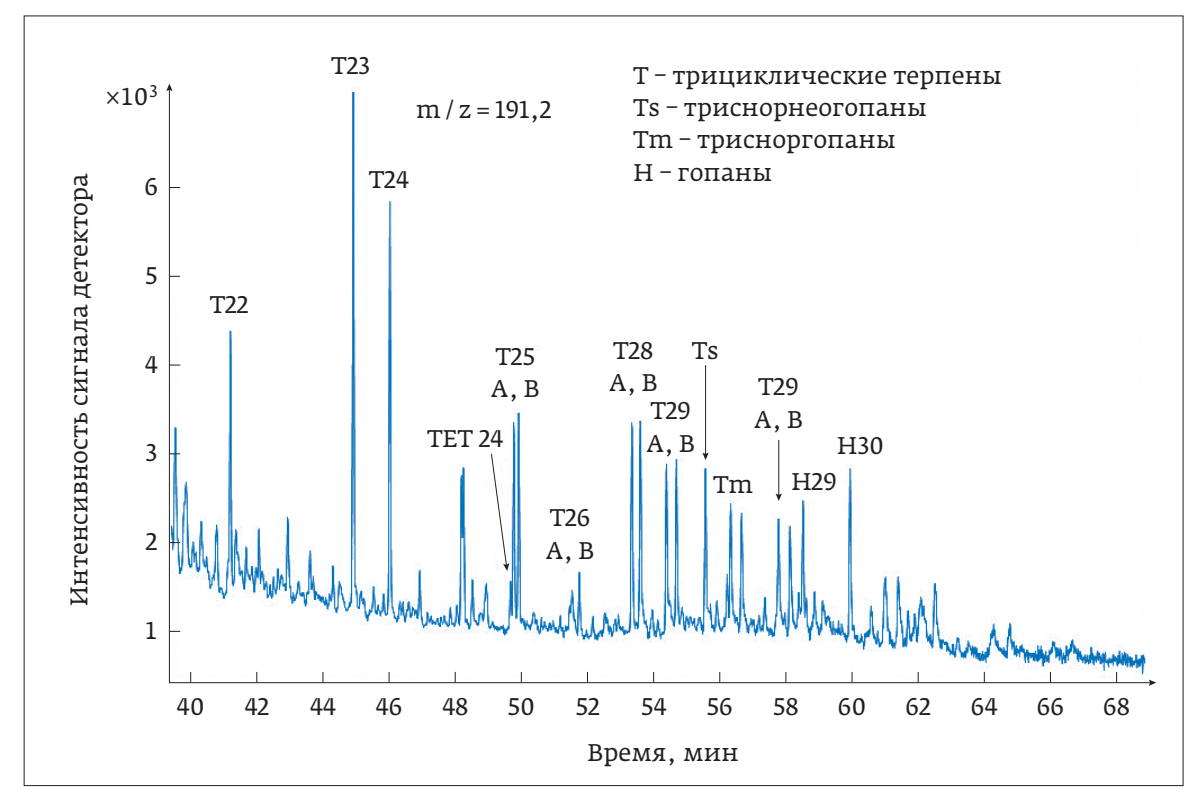

Puc. 5. SIM-хроматограмма по иону $\mathrm{m} / \mathrm{z}=191,2$, характерному дяя терпенов и гопанов 


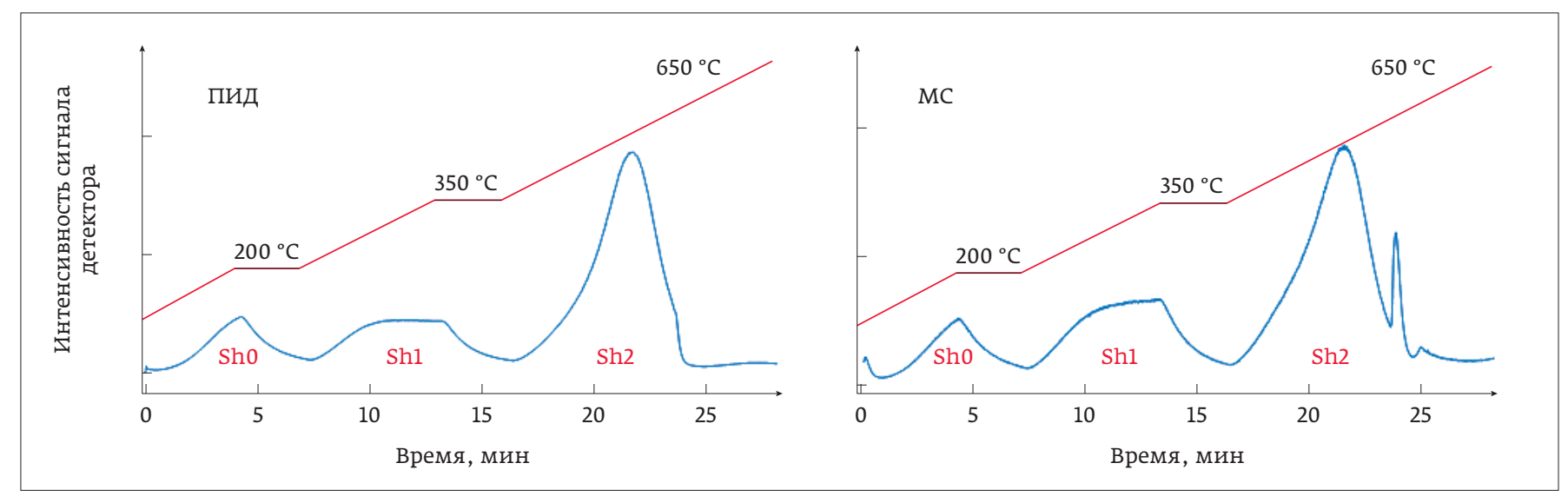

Puс. 6. Пирограммы, полученные с помощью альтернативной температурной программы пиролиза ОВ

объекта исследования без дополнительной подготовки образцов.

\section{ЛИТЕРАTУPA / REFERENCES}

1. Using Py-GC/MS for the comprehensive evaluation of Source Rock. Presented by Frontier Lab. at the Gulf Coast Conference, Galveston, TX, 2014.

2. МИ № 205-02/RA.RU.311787-2016/2018. Методика измерения массовой доли суммы свободных углеводородов, массовой доли суммы углеводородов пиролиза нерастворимых органических веществ в пробах нефтеносных горных пород методом пиролитической хроматографии. MT. № 205-02/RA.RU.311787-2016/2018 Methods of measuring the mass fraction of the sum of free hydrocarbons, the mass fraction of the sum of hydrocarbons of pyrolysis of insoluble organic substances in samples of oilbearing rocks using pyrolytic chromatography. Metodika izmerenija massovoj doli summy svobodnyh uglevodorodov, massovoj doli summy uglevodorodov piroliza nerastvorimyh organicheskih veshhest $v$ probah neftenosny hornyh porod metodom piroliticheskoj hromatografii.

3. Romero-Sarmiento M., Pillot D., Letort G., Lamoureux-Var V., Beaumont V., Huc A. and Garcia B. New Rock-Eval Method for Characterization of Unconventional Shale Resource Systems // Oil \& Gas Science and TechnologyRev. IFP Energies nouvelles. 2016. V. 7. 37.

4. Abrams M., Gong C., Garnier C., Sephton M. A new thermal extraction protocol to evaluate liquid rich unconventional oil in place and in-situ fluid chemistry // Marine and Petroleum Geology. 2017. V. 88. P. 659-675.

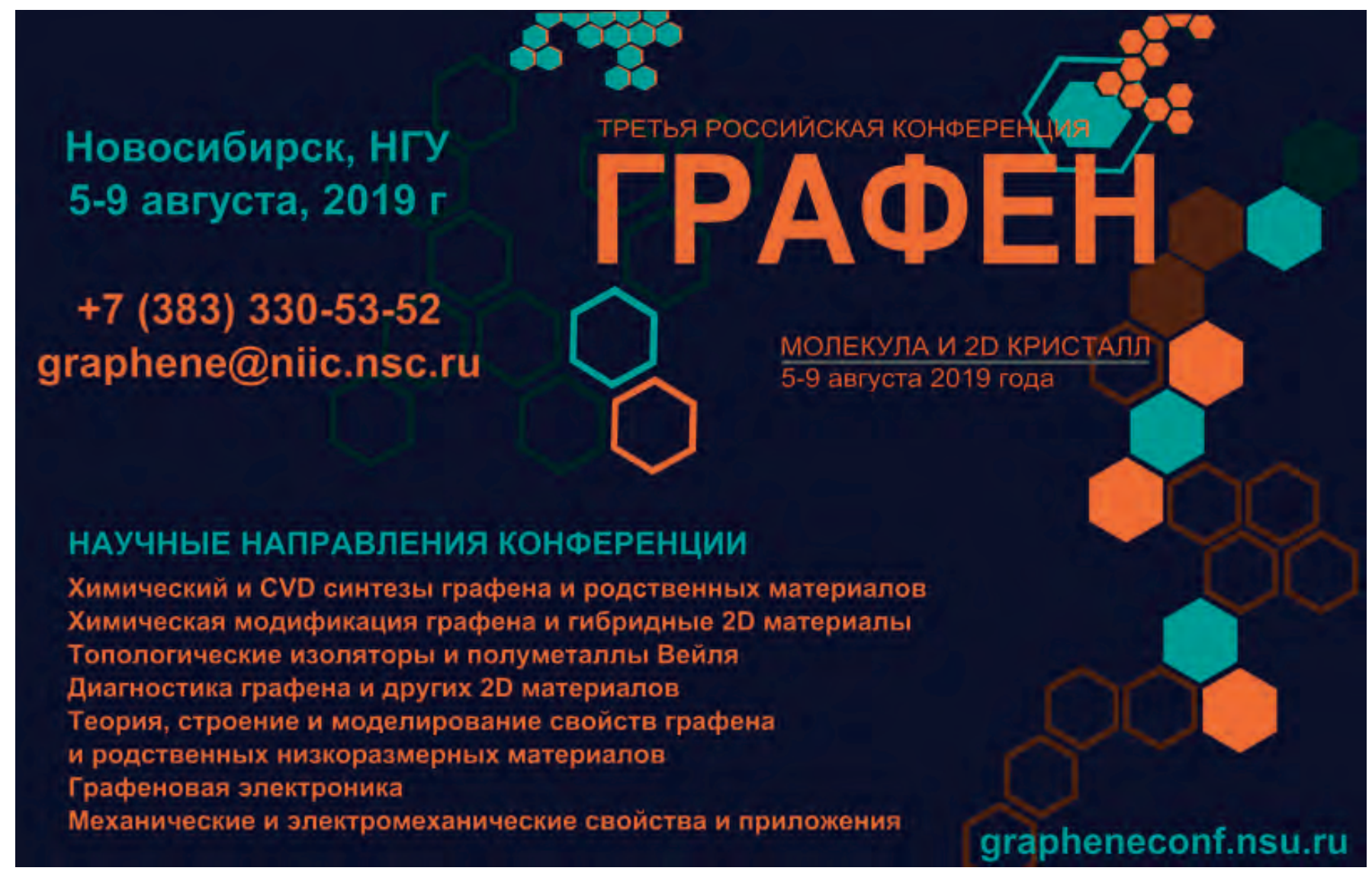

